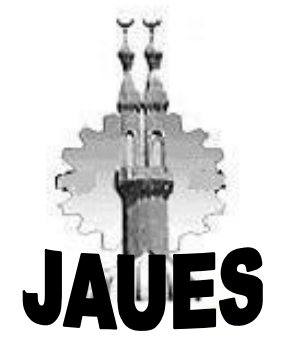

Journal of Al-Azhar University Engineering Sector

Vol. 14, No. 53, October, 2019, 1465-1473

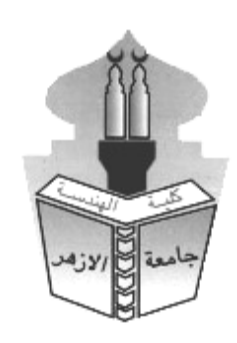

\title{
ON THE EVALUATION OF "NHTSA" AUTOMOTIVE FE MODEL IN HEAD ON CRASH USING ANSYS LS-DYNA SYSTEM AGAINST "IIHS" TEST.
}

\author{
Ahmed Z. Salem. \\ Faculty of Engineering, Civil Eng. Dept. King Abdulaziz University, Jeddah, K.S.A. \\ E-mail: :azsalem@hotmail.com
}

\begin{abstract}
.
Simulations of automotive crash are now a well-established instrument for ensuring occupants safety at most types of crash scenarios and improving the car design accordingly when needed. Many Automotive crash simulation's systems are available currently, where each system strives to attain ease of use, high accuracy, and consuming the least possible computer time in running the crash scenario. However, most of these systems are used independently. A unique exception of these systems is ANSYS LS-DYNAYwhere the two systems can be used as one unit in ANSYS explicit module, where one can combine the ease of use of ANSYS with the world class suite of LS-DYNA.This system is quite straightforward to modify the car model, change elements attributes, redefine the elements integration rule, and spotweld definitions to achieve less running time while keeping almost the same accuracy.

This paper presents an evaluation of a modified National Highway Traffic Safety Administration (NHTSA) finite element model of Ford truck structure.The model structure is first imported to ANSYS LS-DYNA simulation system to facilitate its handling, modification, and applying different simulation scenarios. Then after modification, it is evaluated through the following three steps: first, evaluated against the ability to rollover almost free of stresses, second, evaluated in a head on crash test at low speeds such as 5 miles/hours. This scenario can happen while moving out of the drive way or in a parking lot area, and third, evaluated in a head on crash test against rigid fixed barrier with 35 miles/hour test simulating the Insurance institute for highway safety (IIHS) test. The results show that the modified model is quite capable of capturing the main characteristics of the three tests adequately.
\end{abstract}

KEY WORDS: Finite Element Model, Crash simulation, Ford truck structure, ANSYS, LS-DYN

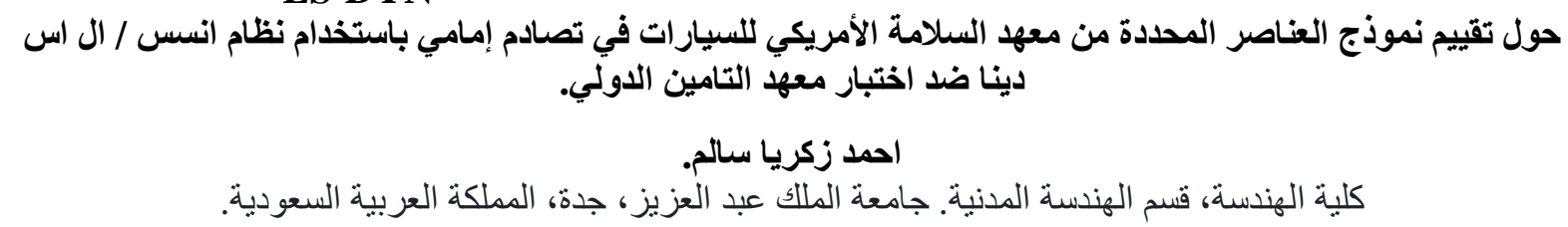

أصبحت محاكاة صدام وحو ادث السيار ات الآن أداة راسخة لضمان سلامة الركاب في معظم أنواع سيناريوهات التصات التصادم

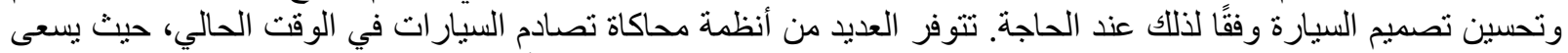

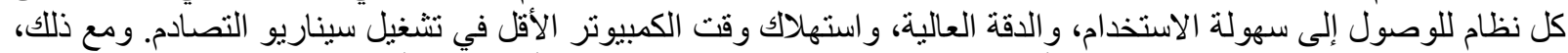
فإن معظم هذه النظم لا تتيح لاستخدامها ألا بشكل مستقل. الاستثناء الفريد لهذه الأنظمة هو أنسس/ ال اس دينا، لفئ حيث يمكن 


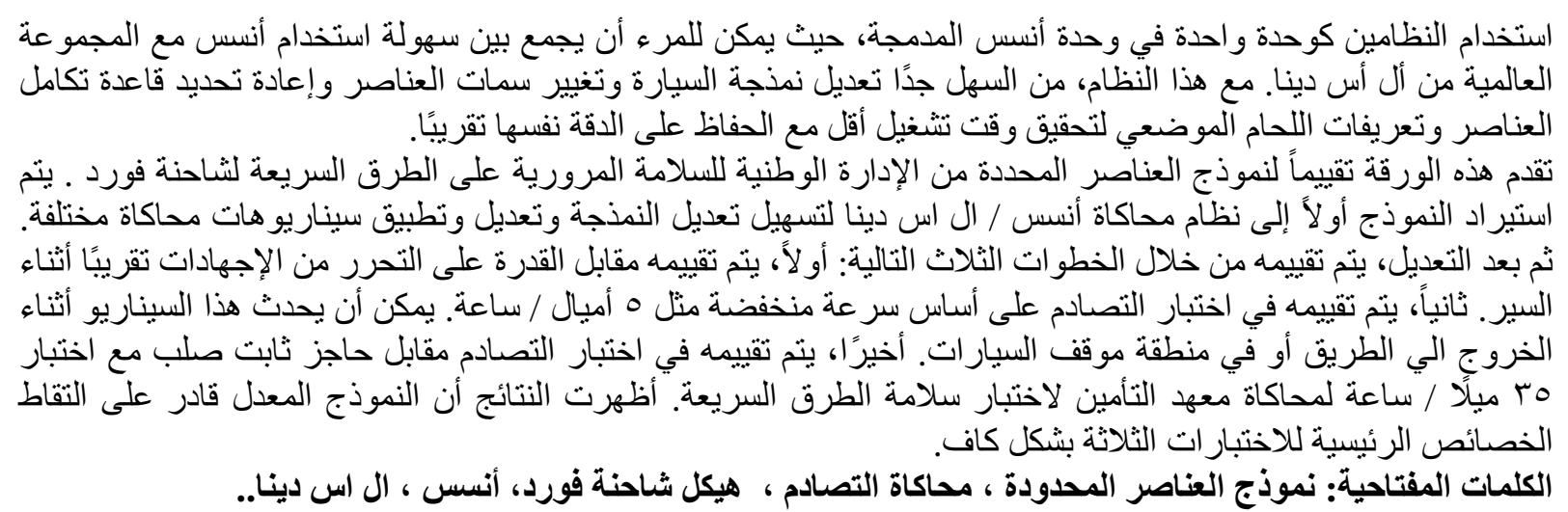

\section{INTRODUCTION.}

\subsection{The need for automotive crash simulation models.}

Automotive design and manufacturing have grown strong in depending on crash simulation tools $[1,2,3$, and 4]. The need for the simulation tools is explained as follows: For the car design to be successful in crash tests and get a "Good" rating [1], it must secure a minimum intrusion of the wheels and the engine/transmission block into the toe pan and dash panel [1] in head on crash. This can be achieved by building several models of the same car with different frontal hardware designs and test them physically until a good design is reached. This process is both lengthy time wise and costly. Alternatively, it can be done by building these serval models only in the simulation system [1, and 3], based on the originally CAD scanned model, until reaching a good design. Then only build this design finally and test it physically. This process is both much cheaper and does not consume that much time. A good example of this process is [1] where the redesign of the vehicle frontal hardware is provided to lessen the intrusion of the wheel and engine/transmission block utilizing the simulation systems. This redesign presented an excellent economical utilization of the least material for reinforcing the toe pan and dash instrumentation panel that can achieve its purpose.

The process of utilizing simulation software in performing crash scenarios during car design phase has led to significant improvements in occupant safety over time. Due to these improvements [5, 6, and 7], between years 2010 and 2015 the number of road fatalities in the European Union (EU) decreased about 17 \% (European Road Safety Observatory, 2017).

Many researchers have directed their attention to study the safety of the automobile during crash scenario. Examples are the revision of crashworthiness [12], bumper beam in low speed frontal collisions [8], Automotive chassis frame [13], Automotive crash Analysis and Reconstruction Means [9], and the vehicle safety systems roles in crash and using these systems to absorb its energy $[15,18,22$, and 23]. These systems include many items such as ABS, airbags, seatbelts, head restraints, anti-intrusion blocks, foldaway steering columns, inner padding, laminated windshields, and crush zones [11].

\subsection{Design challenge for the model.}

The Finite element model faces many challenges to produce very accurate results, while keeping the computer running time reasonable to perform as many as needed simulation scenarios without being held by time. The recent direction [1] to refine the mesh as fine as possible - including the internal hardware of the car, instruments, and as much details as possible - could lead to lengthy simulations time wise. This led some researches to try to simplify the model as much as possible, while still capturing the main attributes of the crash scenarios [19, and 20]. The simplification is done by using parametric simulation of several controlled accident variables, with case results weighted by the relative frequency of each specific event in [19], and by modelling the Vehicle as a 2D model in [20]. The direction in this paper is to only simplify the model in terms of parts, 
element types, integration rules and spot weld definitions as they are among essentials that consume the most simulation time.

\section{Finite Element Model.}

The Ford finite element model of NHTSA [1] is an LS-DYNA input deck. The LS-DYNA finite element software is considered industry standard for both crash simulation and modeling [16]. ANSYS LS-DYNA [21] offers much higher usability especially for ANSYS user base. Importing the LS-DYNA Finite element model to ANSYS through database system conversion [21] insures high usability and simplicity of use to apply modifications and perform many crash studies. The structure of the imported model is shown in Fig. 1 below.

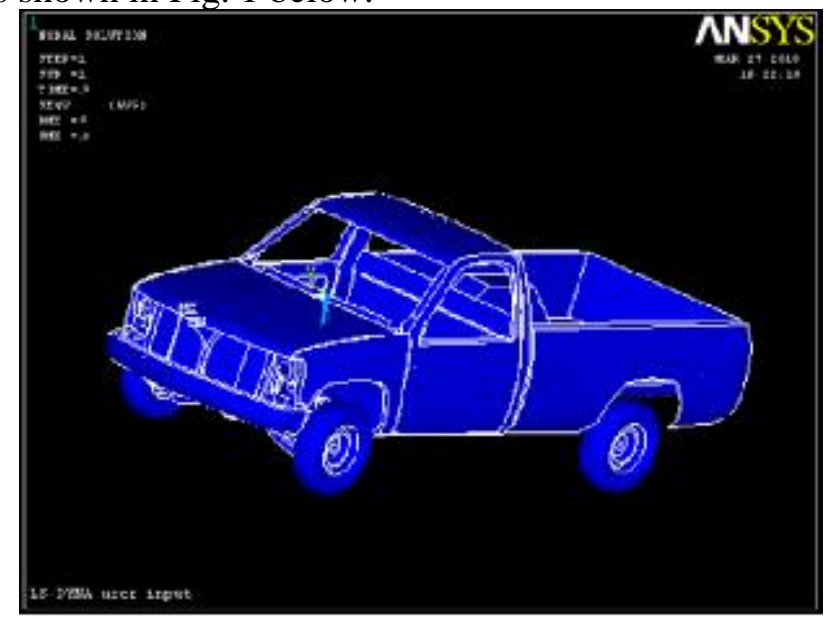

Fig. 1. The structure of the Imported NHTSA model of the Ford Truck to ANSYS LS-DYAN System.

After importing the model, it was modified to reduce parts and calculations of elements while keep almost the same accuracy. The modified model consists of about 300 Parts, 0.6 million Nodes, 0.5 million shell elements, 30 thousand brick elements, and 2 thousand beam elements. The total weight is about $1782 \mathrm{~kg}$ [14].

The Shell elements [16], integration points through thickness [16], and spot welds [16, 17, and 18] are also changed to speed up the calculations and reduce the simulation run time on the computer. These changes are shown below in Table 1.

Table 1. Changes in Shell elements type, integration points through cross section, and Spotweld definitions.

\begin{tabular}{|l|l|l|}
\hline \multicolumn{1}{|c|}{ Element } & \multicolumn{1}{|c|}{ ANSYS Model } & \multicolumn{1}{c|}{ NHTSA Model } \\
\hline Shell Element & $\begin{array}{l}\text { Reduced Integration Belytschko Tsay } \\
\text { element with Hourglass control. }\end{array}$ & $\begin{array}{l}\text { fully integrated Bathe-Dvorkin shell } \\
\text { element. }\end{array}$ \\
\hline $\begin{array}{l}\text { Shell Element } \\
\text { Integration points. }\end{array}$ & 3 integration point through thickness. & $\begin{array}{l}\text { 5-point integration option for major } \\
\text { load path parts. }\end{array}$ \\
\hline Spot Weld & Node pinning. & $\begin{array}{l}\text { mesh-independent Hexa solid weld } \\
\text { element. }\end{array}$ \\
\hline
\end{tabular}

Also, mass scaling was enabled [16], allowing LS-DYAN to add very marginal mass to critical elements to bolster the maximum allowable time step for those elements. 


\subsection{Testing the FE Model.}

2.1.1 Rollover test.

This test is used to evaluate the behavior of the model structure under no loading conditions. Just the initial constant velocity as a boundary condition. It simulates a truck moving on the highway with constant speed. In ideal road and perfect conditions, the truck structure should experience minimum stresses. The test runs for 10,000 iteration sub steps to cover a time interval of $0.15000 \mathrm{sec}$. [21]. This time is chosen based on the assumption that most crash scenarios do not exceed $0.12000 \mathrm{sec}$. period [1].

The test results are shown below in Figs. 2 and 3 at the following selected time intervals shown in Table 2. For this test, there is no target facing the truck and no crash takes place. In the next simulations with targets, the same reporting time table will be used.

Table 2: Time sequence of the results in the Figures.

\begin{tabular}{|c|c|l|}
\hline Stage & Time (sec.) & \multicolumn{1}{c|}{ Description } \\
\hline 1 & 0.000000 & Start position. No loading, and no contact with target. \\
\hline 2 & 0.075000 & Middle position. Full loading and Full contact with target. \\
\hline 3 & 0.150000 & Final position. End of crash simulation duration. \\
\hline
\end{tabular}
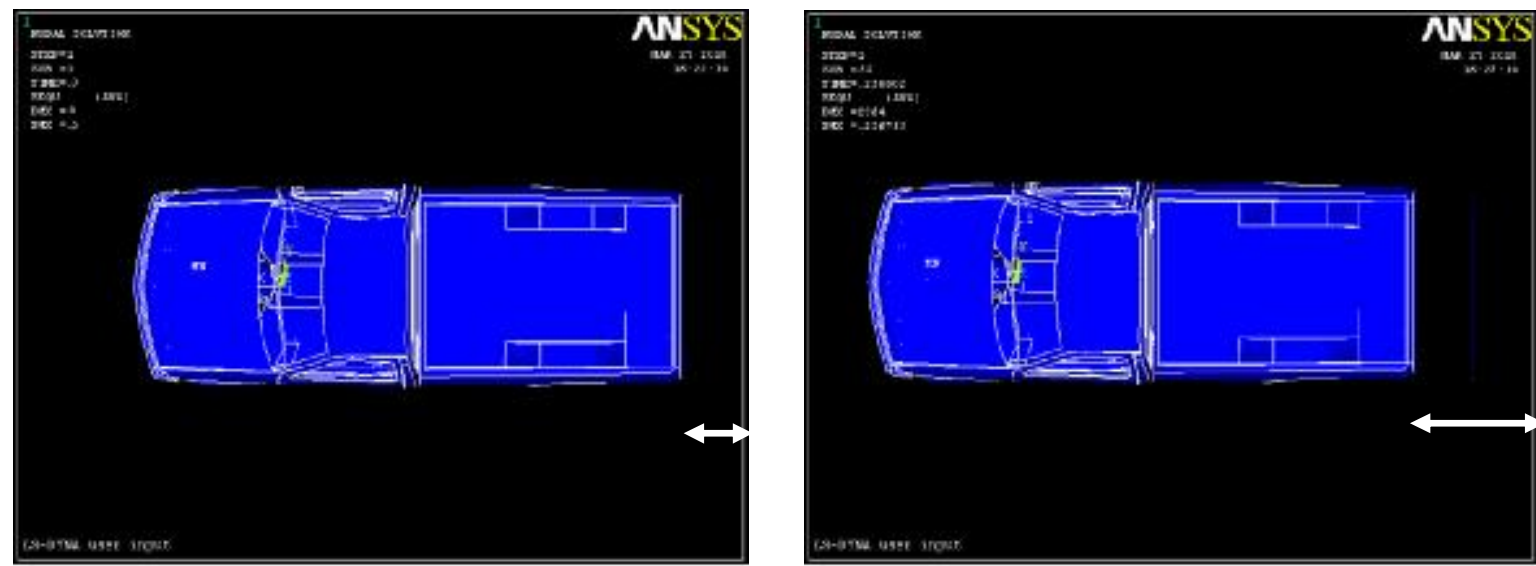

Fig. 2. The Rollover test of the NHTSA model. Left, initial position at time $=0.0000$ sec. Right position at time $=.07500 \mathrm{sec}$.

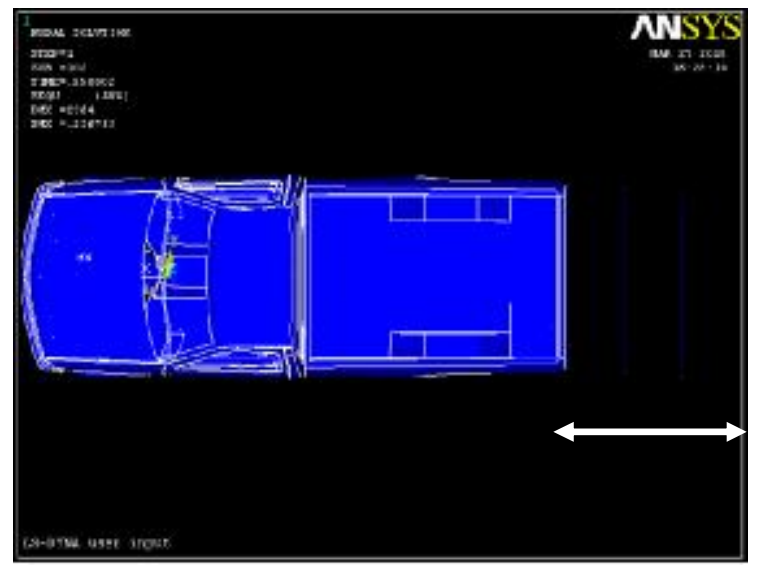

Fig. 3. The Rollover test of the NHTSA model position at time $=.15000$ sec. 
The progress of the test is indicated in Figs. 2 and 3 with the bold while arrow. It indicated how far the truck structure has moved with time from its original positions. The model passed the test successfully as no stresses are introduced while advancing in its rollover.

\subsubsection{Head on Crash test with 5 miles/hour test.}

This test is used to evaluate the integrity of the model in terms of the contact elements and surfaces definitions mainly. It is used in automotive design to ensure the minimum damage to the car safety system [19] at those speeds. Also, is it used to design the car front in such a way it needs minimum repair cost in this crash scenario [3]. The test is performed against a rigid fixed barrier for 0.15000 sec. Figures 4 and 5 below show the test progress from the top view of the model. The Figures show the results at times 0.0000 sec, $0.07500 \mathrm{sec}$. and $0.15000 \mathrm{sec}$. respectively as in Table 2 above. Figures 4 and 5 show that the damage to the car safety system is minimum as the system is remained intact. The model captured the phenomena of car rebound after contact with the rigid barrier.
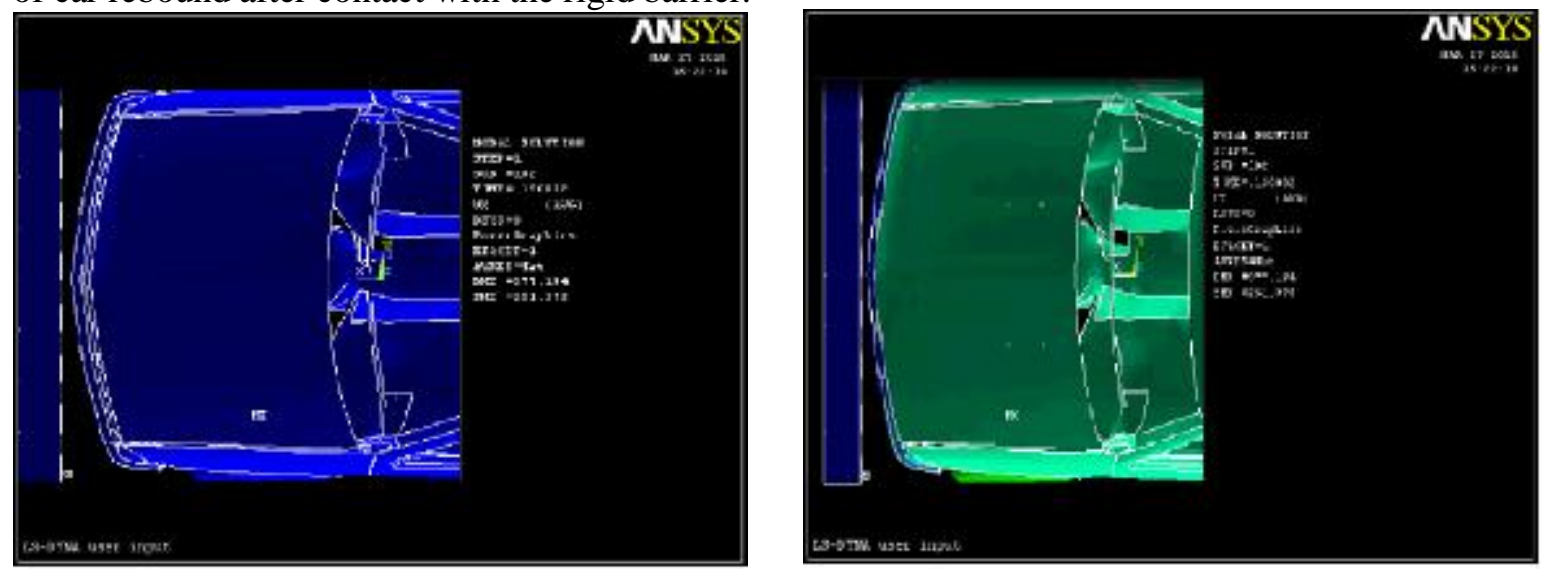

Fig. 4. The plan view of the frontal crash test under low speed of 5 miles/hour. Left, starting position. Right, crash at time $=.07500 \mathrm{sec}$.

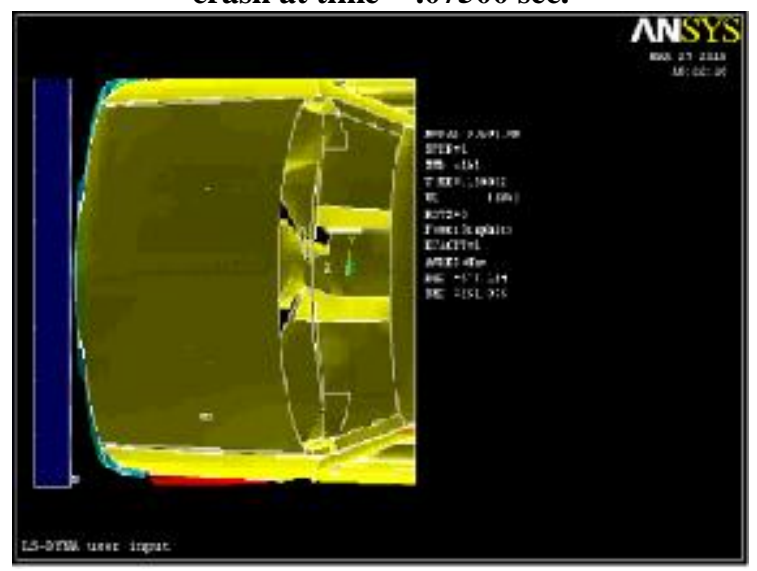

Fig. 5. The plan view of the frontal crash test under low speed of 5 miles/hour. Crash at time $=.15000$ sec. Figs. 6 and 7 below show the results at times $0.00000,0.07500$ and 0.15000 from below the model. 

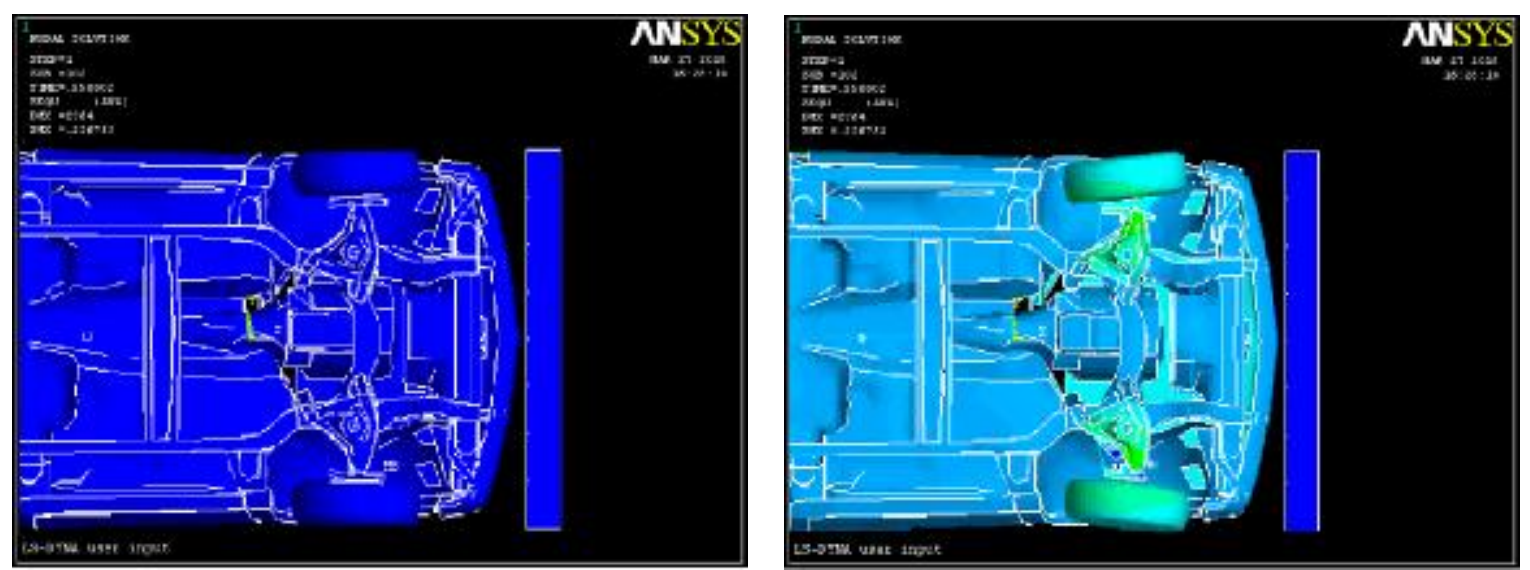

Fig. 6. The bottom view of the frontal crash test under low speed of 5 miles/hour. Left, starting position. Right, crash at time $=\mathbf{. 0 7 5 0 0 ~ s e c . ~}$

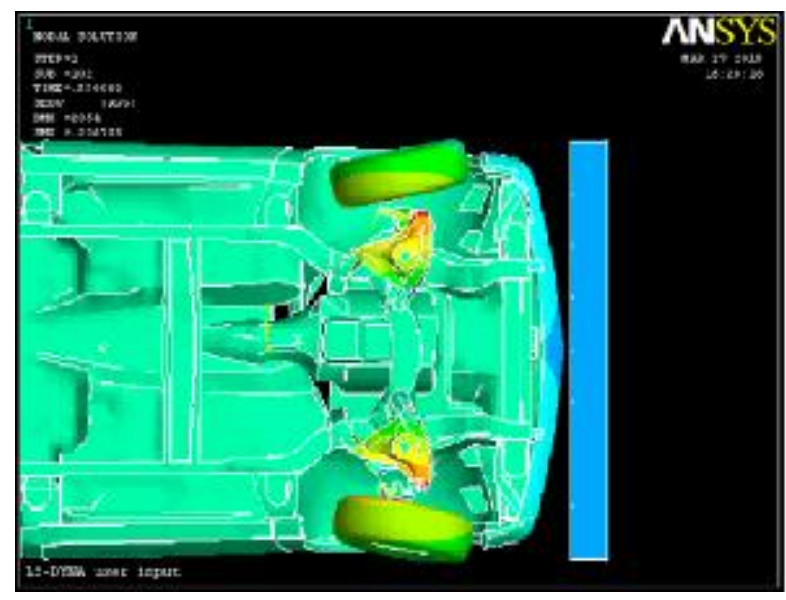

Fig. 7. The bottom view of the frontal crash test under low speed of 5 miles/hour. Crash at time $=.15000 \mathrm{sec}$.

3. EVALUATING THE FM MODEL AGAINST REAL MODEL.

The imported finite element model is used in a head on crash simulation with conditions close to those of the real test by IIHS [4]. The approaching speed is set to 35 Miles/hour against a fixed rigid barrier and the simulation time is set to 10,000 sub iterations as before. The model is oriented to have a head on crash with the barrier.

4. RESULTS.

The results are shown in Figs. 8 and 9 below according to time stages in Table 2. The Figures show the results side by side with the physical IIHS [4] test captured at the three times in Table 2. 

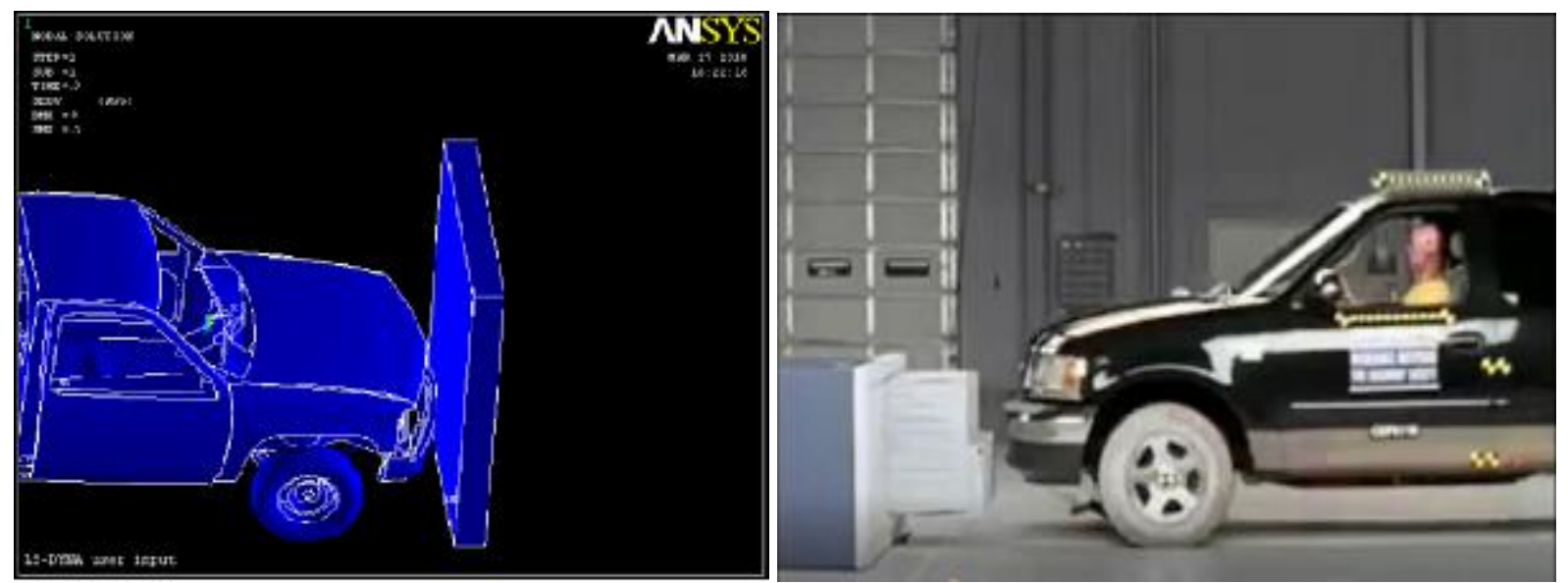

Fig. 8. The frontal crash at speed of 35 miles/hour. Left FE model. Right the IIHS test. Time $=0.00000 \mathrm{sec}$.
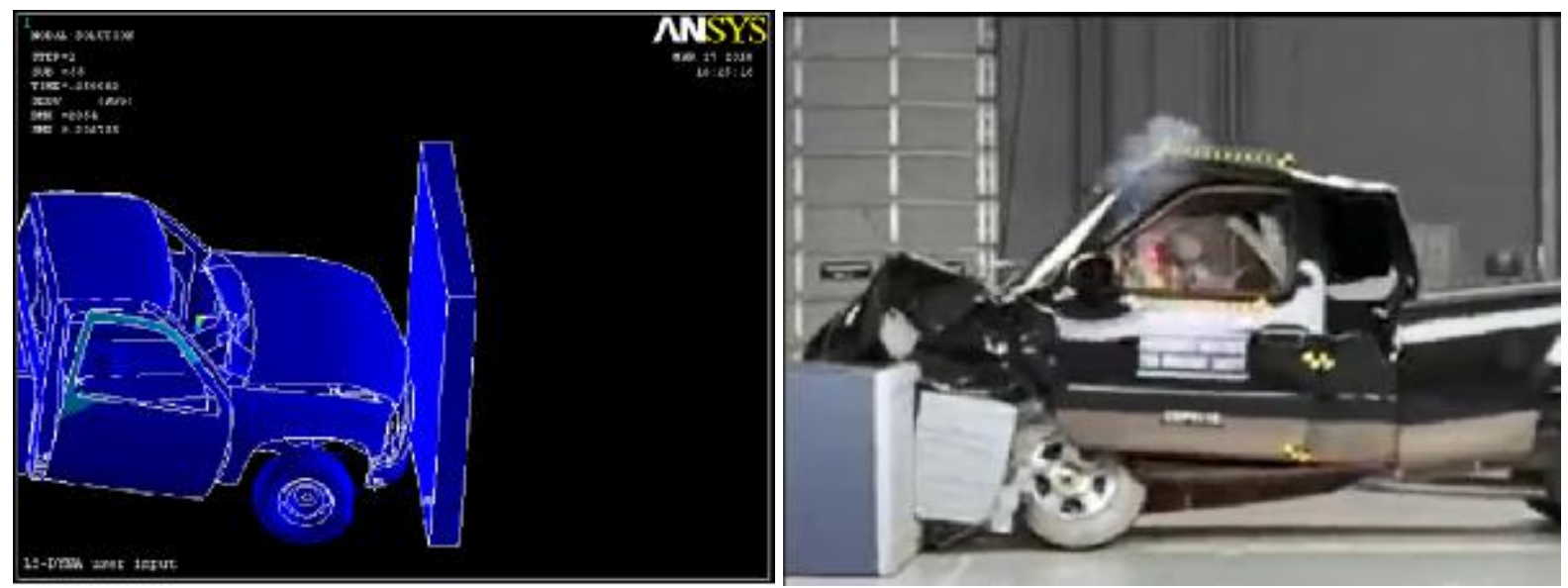

Fig. 9. The frontal crash at speed of 35 miles/hour. Left FE model. Right the IIHS test. Time $=0.07500$ sec.
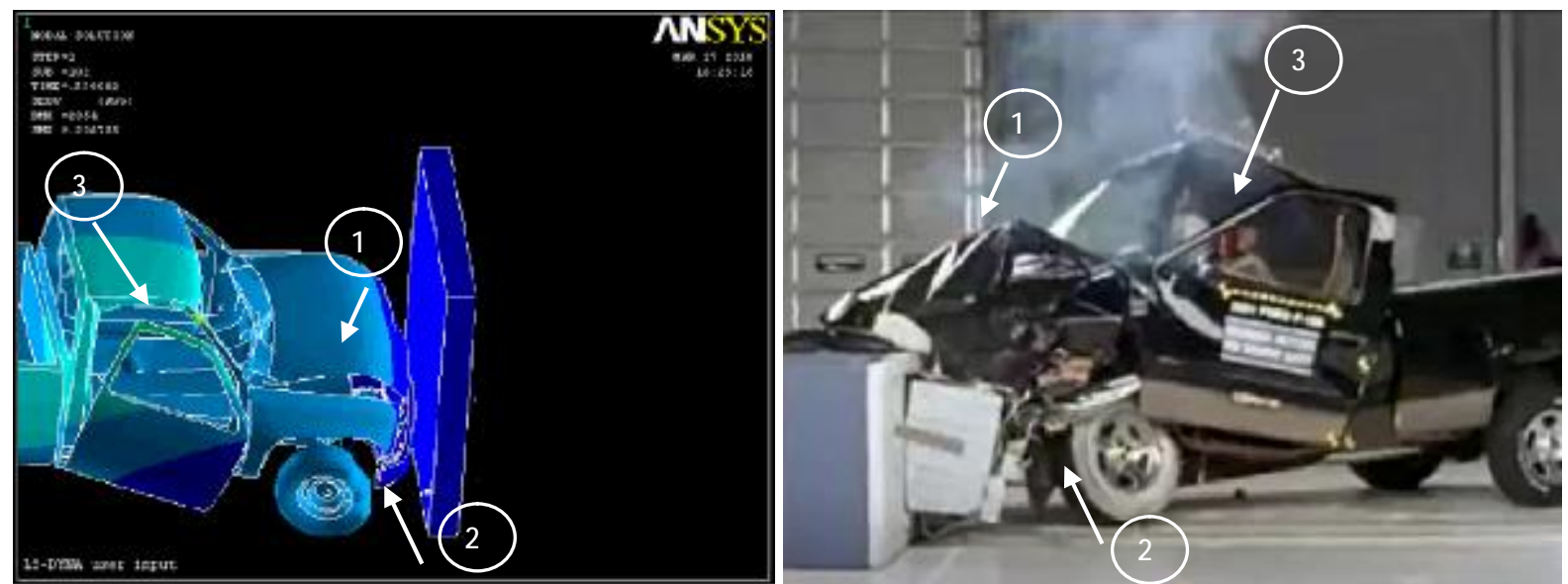

Fig. 10. The frontal crash at speed of 35 miles/hour. Left FE model. Right the IIHS test. Time $=0.15000$ sec. 
Figures 9 and 10 depicted that the model has captured the main three attributes of the test indicated in the figures with the three white arrows namely: the out-of-plan buckling of the front hood with the intrusion of the engine/transmission block towards the toe pan and instrumentation panel, the explosion of the wheel and damage of wheel assembly, and the failure of the door mechanism.

\section{DISCUSSION}

The model simulation conforms to the test results as shown in the Vehicle XG Pulse graph in Figure 11 below [1] without significant loss of accuracy for this specific test. It shows the Vehicle XG pulse measured at the middle node of the toe pan center panel. The simulation forms almost a lower bound to the test results [1, and 4], as it is a simplified finite element representation of the real model. Also, the hourglass control, while enhanced the dynamic stability, contributes directly to this behavior.

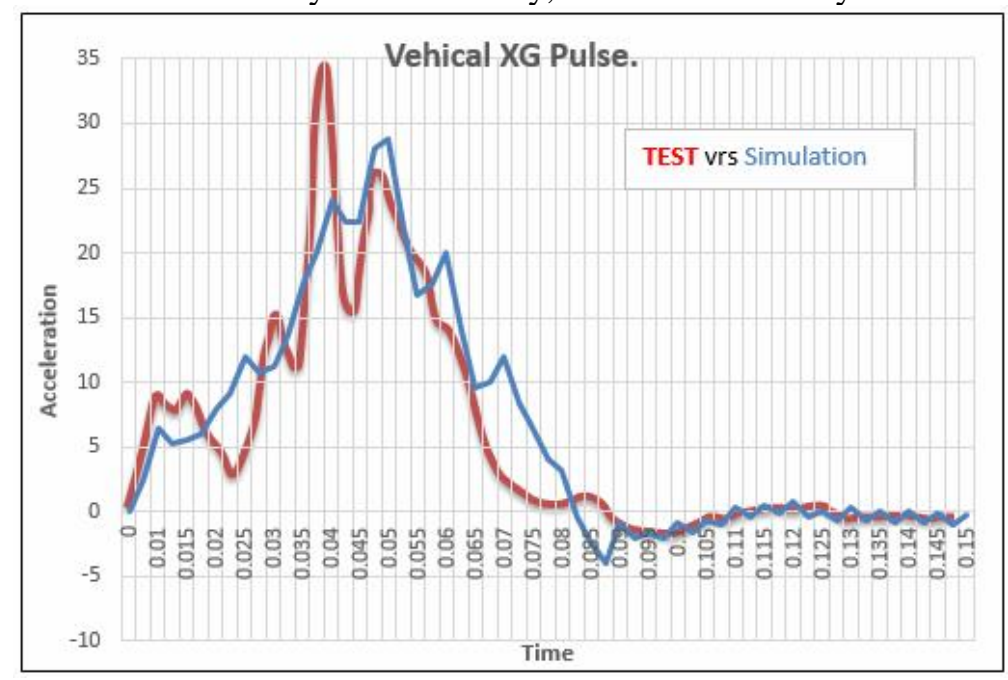

Fig. 11. The Vehicle XG Pulse graph of the test (red) and the Simulation (blue).

\section{CONCLUSION}

The imported NHTSA Ford truck finite element model to ANSYS LS-DYNA system can capture the main attributes of the three simulation scenarios presented in this paper after some simplifications. Importing the model into ANSYS system contributed to the easiness of modifications and performing many crash tests with simplicity. The model structure performed as expected in the rollover test for the full simulation time duration where it exhibited no stresses. The model also showed the expected behavior in the low speed head on crash simulation with fixed rigid barrier. The safety system of the car model is kept intact, and the front of the car model suffers minimal damage. The head on crash simulation with speed of 35 miles/hour showed that, the model is capable of simulating to some extent the main three attributes namely, collapse of frontal hardware, punching and explosion of the wheel and dislocation of the driver door.

\section{REFERENCES}

1. Singh, H., Ganesan, V., Davies, J., Paramasuwom, M., Gradischnig, L., Wood, P., \& Mogal, V. (2018, April). Structural countermeasure/research program: Mass and cost increase due to oblique offset moving deformable barrier impact test (Report No. DOT HS 812 523). Washington, DC: National Highway Traffic Safety Administration.

2. NHTSA. Washington, DC. USA. 2018. Crash Simulation Vehicle Models (Web page). Available at www.nhtsa.gov/crash-simulation-vehicle-models.

3. Kirkpatrick, S. W., July 2000. Development and Refinement of Vehicle Models of a 1997 Ford Crown Victoria, Applied Research Associates, Inc. 
4. Insurance institute for highway safety test. YouTube channel At: https://www.youtube.com/watch?v=6Wb66PzljP8 Access: 2019.

5. European Road Safety Observatory, 2017. Annual Accident Report.

6. European Commission, 2010. Road Safety Program 2011-2020: detailed measures, European Commission.

7. Euro NCAP. 2012. "Frontal impact testing protocol", European new car assessment program (Euro NCAP), version 6.0.

8. J. Marzbanrad, M. Alijanpour, M. SaeidKiasat. 2009. Design and analysis of an automotive bumper beam in low-speed frontal crashes, Thin-Walled Structures $47 \mathrm{pp}$ 902-911.

9. Brach, R. M. \& Brach, M. R., 2005. Vehicle Accident Analysis and Reconstruction Methods.

10. Warrendale, PA, USA: SAE International, ISBN 0-7680-0776-3.

11. Wei, Z., Karimi, H. R. \& Robbersmyr, K. G. 2016. Analysis of the relationship between energy absorbing components and vehicle crash response. Tech. Rep. 2016-01-1541. SAE Technical Paper, Issue 2016-01-154.

12. P. Prasad, J. E. Belwafa, P. Bois, C. C. Chou, B. B. Fileta, T. B. Khalil, A. I. King, H. F. Mahmood, H. J. Mertz, and J. Wismans. 2004. "Vehicle crashworthiness and occupant protection", AISI.

13. J. Ambrósio. 2010. Automotive structural crashworthiness and occupant protection. in G. Mastinu, and M. Ploeck, "Road and off-road vehicle system dynamics handbook", Taylor and Francis, London, UK.

14. T. A. Babu, D. V. Praveen, and M. Venkateswarao. 2012. Crash analysis of car chassis frame using finite element method. International Journal of Engineering Technology and Research. 1(8).

15. Ford. "Ford Media (F150 Specification)", available online at: http://media.ford.com/images/10031/2012_F150_Specs.pdf. Access: 2019.

16. Ahmed Elmarakbi, Yee Xin Long, John MacIntyre. 2013. Crash analysis and energy absorption characteristics of S-shaped longitudinal members. Thin-Walled Structures. 68. pp 65-74.

17. Livermore Software Technology Corporation. LSDYNA keyword user's manual, volume II: Material models (Revision 1275, Version 971). Livermore, CA: Author. Available at: www.dynamore.de/en/downloads/manuals/ls-dyna-manuals/ls-dyna-971-manual-vol-iimaterial-models/at_download/file Access: 5-2019.

18. Malcolm, S., \& Nutwell, E. Spotweld Failure Prediction Using Solid Element Assemblies. 6th European LS-DYNA Users' Conference, Gothenburg, Sweden, 2007. May 29-30.

19. Chao, Y. J. 2003. Ultimate strength and failure mechanism of resistance spot weld subjected to tensile, shear, or combined tensile/shear loads. Journal of Engineering Materials and Technology, Vol. 23.

20. Alexandra C. Kuchar. 2016. A SYSTEMS MODELING METHODOLOGY FOR ESTIMATION OF HARM IN THE AUTOMOTIVE CRASH ENVIRONMENT. Volpe National Transportation Systems Center, USDOT, USA, ESV Paper Number 354.

21. Dario Vangi, Filippo Begani, Michelango-Santo Gulino, Florian Spitzhutt. 2018. A vehicle model for crash stage simulation. IFAC Papers, 51-2. 837-842.

22. ANSYS Inc. Website https://www.ansys.com/products/structures/ansys-ls-dyna Access: 5-2019.

23. Iraeus, J. \& Lindquist, M., 2015. Pulse shape analysis and data reduction of real-life frontal crashes with modern passenger cars. Int. J. Crashworth., 20(6).

24. M. Pahlavani, J. M., 2015. Crashworthiness study of a full vehicle- lumped model using parameters optimization. Int. J. Crashworth., 20(6), pp. 573-591. 